\title{
IDENTIFYING USERS' REQUIREMENTS OF GEOGRAPHIC INFORMATION FOR DISASTER RISK MANAGEMENT IN THE DOMINICAN REPUBLIC
}

\author{
G. Rosario Michel ${ }^{1,2^{*}}$, S. Muñoz Tapia ${ }^{2}$, V. Guzmán Javier ${ }^{2}$, J. Crompvoets ${ }^{1}$ \\ ${ }^{1}$ Public Governance Institute (PGI), KU Leuven, Belgium - joep.crompvoets@kuleuven.be \\ ${ }^{2}$ Servicio Geológico Nacional. 10148 Santo Domingo, República Dominicana - grosario@sgn.gob.do
}

\section{Commission IV}

KEY WORDS: User Requirements, Disaster Risk Management, Emergency Mapping, Geographic Information, Small Island Developing States, Caribbean Region, Dominican Republic

\begin{abstract}
In recent years, the growth of public available geographic information and location-based services has been enabling more stakeholders from diverse backgrounds to participate in generating and sharing a comprehensive view of the territory to reduce the impact of severe phenomena in the communities. With the prediction of more disastrous phenomena in the Caribbean region, understanding of what and how to be prepared beforehand to meet users' needs from different sectors should facilitate to react quickly and take full advantage of geospatial technology and resources to support disaster managers and citizens. This paper is mainly focused on the identification of users' requirements of geographic information and services for disaster risk management (DRM) in the Dominican Republic. The results are built upon an online survey targeted to expert and non-expert users that intervene in the National System of Prevention, Mitigation and Response (SN-PMR, in Spanish). Our findings revealed seven major users' requirements for DRM: (1) policy for sharing geo-information; (2) implementing a disaster-oriented SDI; (3) technical standards for real-time data collection; (4) simplified procedures for gathering and accessing of metadata; (5) mobile applications (App) for data collection and alerts visualization; (6) more capacity building programs; and, (7) closer community participation using social networks. This knowledge will contribute to a superior level of readiness to prevent future disasters in Dominican Republic and to support potential studies/practices in the Caribbean region and other Small Island Developing States in the World, which share similar challenges in terms of natural hazards and development issues.
\end{abstract}

\section{INTRODUCTION}

\subsection{General Introduction}

Different types of dangerous events, including natural and manmade hazards and related environmental, technological and biological hazards, have been seriously threatening the wellbeing of the society in different aspects. These phenomena might cause multiple human, economic, social and environmental losses. In this sense, international organizations have highlighted the fact that sustainable development cannot be achieved unless disaster risk is reduced (UNISDR, 2015b).

In case of the Dominican Republic (DR), as a small island developing state (SIDS) in the Caribbean region is continuously exposed to a wide range of natural disasters, e.g. seismic and hydrometeorological events. DR average annual losses due to multi-hazards effects reach over 1 billion US dollars each year, which represents 23.8 percent of its annual social expenditures (PreventionWeb, 2014).

Geographic information (GI) and services have made significant contributions as strategic tools to support disaster risk management (DRM) efforts. Disaster risk management refers to a full lifecycle of actions comprising four phases: disasters' prevention, mitigation, recovery and reconstruction (UNISDR, 2015a). DRM requires GI and services to generate a comprehensive view of where, what, and when events and resources are located to effectively reduce and mitigate the impact of potential hazards in the communities (Goldblatt et al., 2020; Ajmar et al., 2015). Among disaster risk managers, there are different domains stakeholders (government agencies, private enterprises, academia and non-governmental aid agencies) with requirements of information and services that change very fast over the disaster risk management lifecycle.

Despite the significant value that can bring to a wide range of stakeholders in charge of DRM efforts, there is a serious gap on the identification of what and how to be prepared beforehand to take full advantage of GI and services in case of disastrous events in developing countries. Therefore, understanding users' requirements becomes a crucial step towards a timely and effective generation and sharing of GI and services for DRM. Users' requirements refers to a user's description of the functionality and performance characteristics of the proposed product (Snoeren et al., 2007).

This paper addresses the following research questions to guide our work: who are the key users, and what are their users' requirements for disaster risk management in the Dominican Republic? This study assumes that disastrous phenomena will lead to a huge demand of geospatial information and services, as more different stakeholders join the disaster risk reduction and response efforts. Therefore, understanding users' requirements will facilitate enabling new and updated information and services to meet a variety of stakeholders' needs. This will lead to a better informed decision-making to address disaster risk management efforts.

Most users' requirements studies primarily focus on the needs of professional end-users and development issues of technology applications for DRM in developed countries settings (Rosario et al., 2020; Menold et al., 2015; Diehl et al., 2006). In this sense, there is a paucity of studies that analyze social-technical, 
including information, technology, policy and standards and human resources, users' requirements for DRM in developing countries contexts - in particular Dominican Republic.

This research aims to identify users' requirements of geographic information and services for disaster risk management in the Dominican Republic as an example of SIDS. The results are built upon a national-level online survey oriented to capture expert and non-expert users' perspectives in order to enhance the use and sharing of geospatial information and services for DRM. To our knowledge, the idea of analyzing users' requirements from a socio-technical perspective, with stakeholders from multiple sectors, academia, the private sector, and both government and non-government organizations from a SIDS, is a novelty.

The contribution of this research is the identification of seven users' requirements that will serve as a basis for being better prepared for future multi-hazard disaster risk management scenarios in the Dominican Republic as well as in other Caribbean SIDS. This knowledge will also contribute to facilitate more users' involvement and adaptation of GI and services to response to DRM efforts.

The paper is structured in the following way. The Dominican Republic context is briefly presented in the remainder of this section. Section 2 explains the research methodology undertaken in this work. In Section 3, we analyze and discuss the main survey results. The paper ends presenting a set of users' requirements for DRM in DR and summarizing our main conclusions (Section 4).

\subsection{Dominican Republic in context}

The Dominican Republic is a small island developing state in the Caribbean region. The limits of the DR are the Atlantic Ocean to the north, the Caribbean Sea to the south, Puerto Rico to the east, and the Republic of Haiti to the west (see Figure 1).

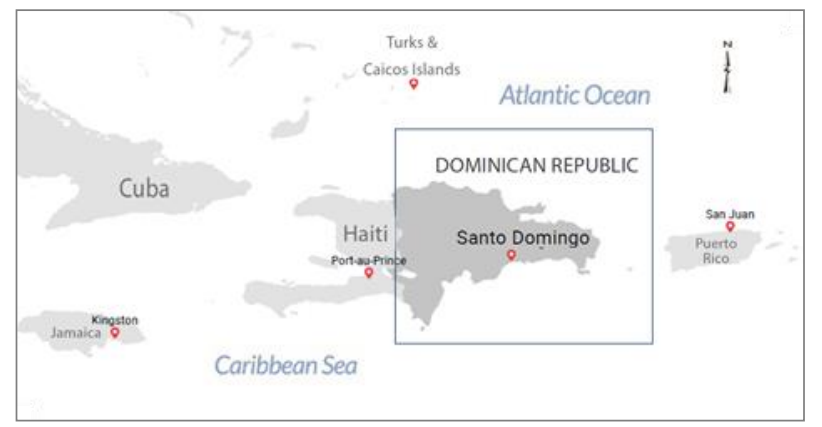

Figure 1. Location of the Dominican Republic in the Caribbean region. Source: National Geological Survey.

The Dominican Republic land area covers a surface of 48,320 $\mathrm{km}^{2}$, with a population of around 9,500,000 inhabitants (National Bureau of Statistic, 2010). The DR's economic growth has been one of the strongest in the Latin America and the Caribbean (LAC) region over the past 25 years (World Bank, 2019).

Each year, from June to November, Dominican Republic, along with most of others Caribbean islands, is exposed to hurricanes and associated hazards (heavy rain, windstorms, and storm surges). These water-related phenomena have represented the worst cause of disasters in term of human life and economic losses (López-Marrero, et al., 2013). For instance, from 2010 to 2016, a total of 44 disaster events have impacted the Dominican Republic, affecting 558,688 people and causing economic damages summing up to US\$ $617,435,000$ (CRED EM-DAT, 2020).

Large earthquakes and tsunamis in DR are constant threats, mainly caused by the interaction of the North American tectonic plate with the Caribbean tectonic plate on which the island is located. Herein, these tectonic plates' interactions have caused several devastating events in recent history in DR. For instance, in 1946 a magnitude 8.1 earthquake triggered a tsunami with waves of up to five meters. This spread damages from the east to the west of the island, causing around 500 deaths (National Geological Survey, 2015).

Law 147-02, on risk management, constitutes the legal framework for disaster risk reduction in the Dominican Republic. It establishes the creation of four major instances for risk management at the national level: (1) National System of Prevention, Mitigation and Response (SN-PMR, in Spanish); (2) National Risk Management Plan and National Emergency Plan; (3) National Integrated Information System; and (4) National Fund for Prevention, Mitigation and Response (National Congress, 2002).

In DR, the coordinator and responsible body for disaster preparedness and response is the Emergency Operations Center, which is part of the SN-PMR and consists of representatives from more than 22 official government agencies. Law 1-12, the National Development Strategy (END 2030), pursues a sustainable management of the environment; effective risk management to minimize human, economic, environmental, and financial losses; and an adequate adaptation to climate change (MEPyD, 2012).

\section{METHODOLOGY}

The methodology used to identify users' requirements of geographic information and services for disaster risk management in the Dominican Republic, consisted of four stages, as proposed by Maguire \& Bevan (2002) (see Figure 2).

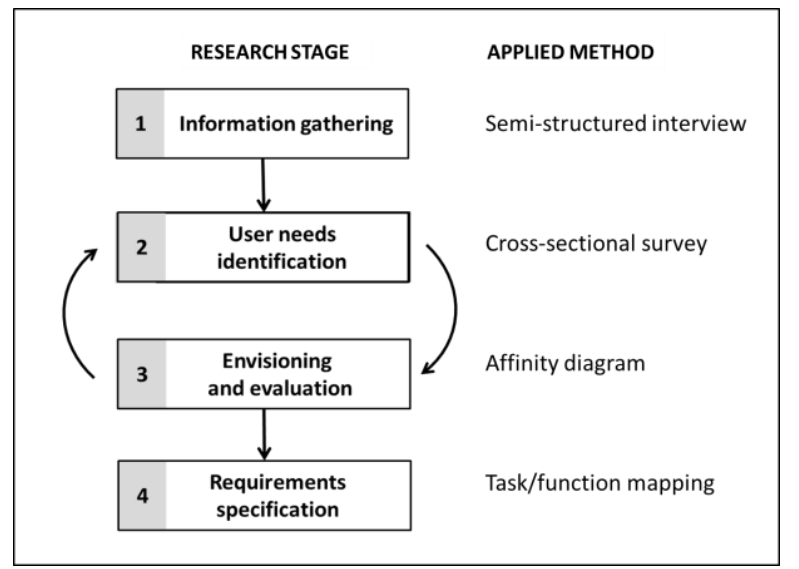

Figure 2. Users' requirements analysis.

Source: Adapted from Maguire \& Bevan (2002).

At first (Stage 1), semi-structured interviews were performed with five senior professionals from disaster response agencies and academia. All interviews were conducted in person. 
The aim of the interviews were to gather background information about the stakeholders, users, processes and interactions that intervene using, generating and sharing geospatial information and services in the DRM context. Based on interviews' outcomes, a list of 316 potential participants was compiled and thus defined the survey population.

To identify users' needs (Stage 2), a national level crosssectional survey was administered, from February to March 2020. Participants were recruited via a request letter, inviting them to provide users' perspective regarding minimum needs to enhance the use and sharing of geospatial information and services for DRM. Participation in the survey was voluntary and anonymous. Expert and non-expert users of geo-information and technologies applied to DRM were targeted to fill out the questionnaire. In this regard, the questionnaire terminology was made understandable for a wide level of respondents.

The questionnaire consisted of 30 questions, divided into five thematic sections:

1. (Q1-Q7): identification of background, role and experience of users with GI in DRM.

2. (Q8-Q14): identification of characteristics, applications and needs of GI for DRM.

3. (Q15-Q21): identification of technological application and needs for using, generating, accessing, processing and sharing of GI for DRM.

4. (Q22-Q25): identification of institutional, policy and standardization needs to enable GI use and sharing for DRM.

5. (Q26-Q30): identification of the capacity building and stakeholders' interaction and needs for handling GI for DRM.

The questionnaire was pre-tested through interviews with geomatics professionals and representatives from disaster response agencies for readability and clarity. The questionnaire was developed and made publicly available using an online Web form. The survey is accessible at the following address: https://forms.gle/KV8puXDo6E57DYey7. The link to the survey along with an invitation letter was sent by email to all 316 identified potential participants. Reminders were sent by email and made by direct telephone call. A total of 130 participants fully completed the survey; hence a response rate of $41 \%$ was achieved, which is considered very high for an online survey. The collected data were sorted and analysed using the SPSS software package.

In order to identify and index themes on users' needs, the affinity diagram technique (Eide et al, 2012) was used (Stage 3). All data relevant to a particular theme were grouped together to form categories under that theme. These categories were the basis for evaluating and specifying users' requirements for the different tasks that they perform. The analysis process ended (Stage 4), applying a task/function mapping technique to document users' requirements (Maguire \& Bevan, 2002).

\section{RESULTS AND DISCUSSION}

This section briefly introduces the questionnaire's thematic sections, followed by the presentation and analysis of the most important results of the survey.

\subsection{Survey population}

A total of 130 participants returned the survey, which representatives from government agencies $(42 \%)$ and private enterprises (39\%) comprising the majority of the sample. The remaining participants came from academia (14\%) and nongovernmental aid agencies (5\%). Up to $40 \%$ of the participants considered themselves as geomatics specialists, followed by senior professionals in geoscience $(13 \%)$, disaster risk management (7\%), ICT and project management each at $6 \%$.

When participants were asked to self-define their organizations' role in the GI market, the majority of participants (who were allowed to select more than one role) reported their organizations as end-users (43\%) and enablers (34\%) of geographic information. Only $23 \%$ of participants defined their organization as producer of GI. In terms of involvement in the DRM lifecycle, more than half of the participants from government agencies and NGOs expressed that mostly intervene in the preparation and mitigation phases (Table 1). Participants from private sector and academia informed the lowest rate of involvement in the whole DRM lifecycle.

\begin{tabular}{|l|c|c|c|c|}
\hline \multirow{2}{*}{$\begin{array}{c}\text { Participants } \\
\text { N= 130 }\end{array}$} & \multicolumn{4}{|c|}{ Users' involvement } \\
\cline { 2 - 5 } & $\begin{array}{c}\text { Prevention } \\
\text { N= 65 }\end{array}$ & $\begin{array}{c}\text { Mitigation } \\
\text { N= 67 }\end{array}$ & $\begin{array}{c}\text { Response } \\
\text { N= 42 }\end{array}$ & $\begin{array}{c}\text { Recovery } \\
\text { N=39 }\end{array}$ \\
\hline Government & $63 \%(34)$ & $61 \%(33)$ & $39 \%(21)$ & $30 \%(16)$ \\
\hline Private sector & $29 \%(15)$ & $33 \%(17)$ & $16 \%(8)$ & $22 \%(11)$ \\
\hline Academia & $61 \%(11)$ & $61 \%(11)$ & $39 \%(7)$ & $33 \%(6)$ \\
\hline NGOs & $71 \%(5)$ & $86 \%(6)$ & $86 \%(6)$ & $86 \%(6)$ \\
\hline
\end{tabular}

Table 1. Users' involvement in the DRM lifecycle. Note: Multiple answers allowed.

Other authors agree with this results when stating that there is a need for the public and private sectors and civil society organizations, as well as academia and scientific and research institutions, to work more closely together and to create opportunities for collaboration, and for businesses to integrate disaster risk into their management practices (UNISDR, 2015b).

\subsection{Geographic information}

Previous research has explored extensively the application of GI for DRM activities (Jones \& Mannix, 2020; Carley et al., 2016; Keiko \& Hayashi, 2012). In our survey, participants' perceived level of importance of GI for DRM, vary widely, though around $50 \%$ of participants ranked census data, satellite imagery and land use datasets, with the highest level of importance. In particular, a large majority (80\%) of participants from government agencies marked geology and hydrology datasets as very important. Similarly, participants from private sector and academia ranked as important, land cover (83\%), topography, and address datasets, each at $80 \%$.

The participants were asked to rank on four-point Likert scales (ranging from not relevant to extremely relevant) relevant cartographic scales for their activities. In this regard, most participants stated that GI at scale below 1:50,000 were extremely relevant. However, up to $43 \%$ participants from academia and NGOs similarly cited that GI becomes relevant at scale 1:5,000. Others authors similarly agreed that importance of geographic information generally increases at a finer scale and with local significance to decision makers (Hatfield Consultants, 2019; Diehl et., 2006). 
A majority of participants indicated to utilize metadata (39\% to a great extent and $30 \%$ to some extent) in supporting the discovery, evaluation, and application of geographic information (Nebert, 2004). Nonetheless, 30\% of participants expressed that metadata of GI is not available in their organizations. A few of participants (11\%) claimed that did not know anything about metadata.

When participants were asked to rank on four-point Likert scales (ranging from not important to very important) a list of features of GI and technologies, up to $61 \%$ of participants suggested that data should be up-to-date or most recent available were the most important attributes (Figure 3). Reliability or quality of information (57\%), followed by visual attractiveness of maps or ease to understand (48\%), were the second most important attributes in the context of DRM. In particular, other study cited visual attractiveness of maps as a relatively less important attribute of GI (Hatfield Consultants, 2019).

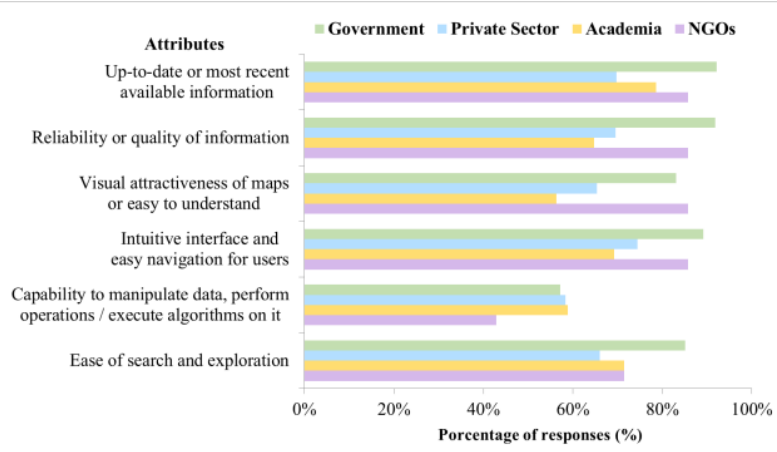

Figure 3. Important attributes of GI and technologies for DRM. Note: Multiple answers allowed.

Participants were also inquired to rank on four-point Likert scale (ranging from not difficult to very difficult) a list of challenges faced while using and accessing GI for DRM. About $50 \%$ of participants most frequently cited restrictions on accessing data, personnel and resourcing as very difficult challenges during DRM tasks. Interestingly, similar number of participants (40\%) rated cost and lack of metadata as the second most difficult challenges. One open question asked participants to mention priority needs of GI for DRM. Our results suggested that there was no significant difference among participants' needs in term of GI for disaster risk management activities (Table 2).

\begin{tabular}{|l|c|c|c|c|c|}
\hline Necessity of geographic information & $\begin{array}{c}\text { GOV } \\
(\mathbf{N}=\mathbf{7 6})\end{array}$ & $\begin{array}{c}\text { PRIV } \\
(\mathbf{N}=\mathbf{4 6})\end{array}$ & $\begin{array}{c}\text { ACAD } \\
(\mathbf{N}=\mathbf{1 7})\end{array}$ & $\begin{array}{c}\text { NGOs } \\
(\mathbf{N}=\mathbf{1 0})\end{array}$ & $\begin{array}{c}\text { TOTAL } \\
(\mathbf{N}=\mathbf{1 4 9})\end{array}$ \\
\hline $\begin{array}{l}\text { Availability of high accuracy } \\
\text { framework GI datasets and metadata }\end{array}$ & 19 & 9 & 5 & 2 & 35 \\
\hline $\begin{array}{l}\text { Current disaster-related datasets at } \\
\text { local/regional/provincial level }\end{array}$ & 19 & 7 & 5 & 1 & 32 \\
\hline High reliable real-time data management & 11 & 9 & 3 & 3 & 26 \\
\hline $\begin{array}{l}\text { Establishment of technical specifications } \\
\text { for data collection and map design }\end{array}$ & 13 & 9 & 1 & 1 & 24 \\
\hline $\begin{array}{l}\text { Procedures for automatization of data } \\
\text { collection and updates }\end{array}$ & 4 & 4 & 1 & 1 & 10 \\
\hline $\begin{array}{l}\text { Technical trainings on collaborative and } \\
\text { rapid mapping tasks }\end{array}$ & 5 & 2 & 2 & - & 9 \\
\hline $\begin{array}{l}\text { More coordination with governments } \\
\text { agencies (funding and partnerships) }\end{array}$ & 3 & 2 & - & 2 & 7 \\
\hline Devices for data collection in the field & 2 & 4 & - & - & 6 \\
\hline
\end{tabular}

Table 2. Users' needs of geographic information.
The availability of high accuracy framework GI datasets and current disaster-related information at different scales were considered with more frequency as priority needs by most participants. Interestingly, participants who were representatives from government organizations claimed that more coordination with other government agencies was needed to enhance the availability of geographic information.

\subsection{Technology}

Geospatial and ICT technologies have widely applied for collecting, organizing, and analysing information from various organizations to response to disastrous circumstances (Goldblatt, et al., 2020; Munenari et al., 2012). In this context, participants were asked to cite main of sources of geographic information. The majority of participants indicated to get information primarily from Google Earth $(89 \%)$ and field surveys $(63 \%)$. Though, spatial data infrastructure (SDI) and social media have proven to have great potential to support stakeholders involved in DRM (Carley, et al., 2016; Genovese \& Stéphane, 2010); our survey results revealed that participants had a low level of utilization of these sources of information.

Regarding communication channels for sharing GI and maps, most participants reported that e-mails $(91 \%)$ and Web pages (66\%) were most frequently used for delivering access to geographic information and map products. Again, survey results denoted that participants had a low level of use of SDI (24\%) to deliver information services. In terms of specific challenges to integrate information for DRM, participants suggested that incomplete or inaccurate information (44\%), inappropriate temporal or spatial scale and lack of metadata, each at about $36 \%$, were the most difficult challenges. Herein, previous research recognized the role of interoperability arrangements to eliminate incompatibility and inconsistency of data, reducing onerous data manipulation before they start using data in their applications (Katalin et al., 2012).

When participants were asked to suggest technology tools to support DRM, participants recommended overwhelmingly that mobile App (92\%), satellite imagery (91\%) and UAV technology $(81 \%)$ should be implemented to enhance effectiveness in capturing and updating information from the affected area (Figure 4). Similarly, other authors have remarked the applications of these technologies to update reference data, in case that is needed and where no other appropriate data sources are available (Ajmar et al., 2015).

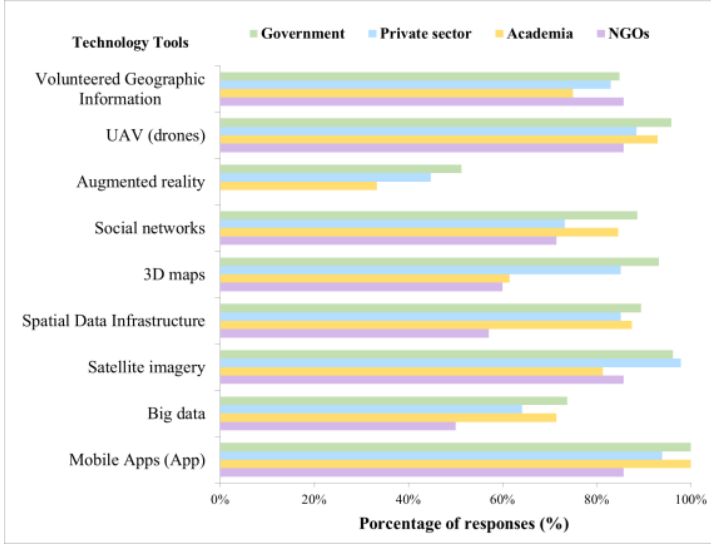

Figure 4. Technology tools for supporting DRM activities. Note: Multiple answers allowed. 
At the end of this survey section, participants were asked to mention priority needs of technology for strengthening DRM activities. A large majority of the participants agreed to suggest implementing a disaster-oriented SDI to facilitate GI exchange with local stakeholders and citizens (Table 3 ).

\begin{tabular}{|l|c|c|c|c|c|}
\hline \multicolumn{1}{|c|}{ Necessity of technology } & $\begin{array}{c}\text { GOV } \\
(\mathbf{N = 2 7 )}\end{array}$ & $\begin{array}{c}\text { PRIV } \\
(\mathbf{N}=\mathbf{2 5})\end{array}$ & $\begin{array}{c}\text { ACAD } \\
(\mathbf{N}=\mathbf{7})\end{array}$ & $\begin{array}{c}\text { NGOs } \\
(\mathbf{N}=7)\end{array}$ & $\begin{array}{c}\text { TOTAL } \\
(\mathbf{N}=\mathbf{6 6})\end{array}$ \\
\hline Develop a national disaster-oriented SDI & 8 & 7 & 2 & 4 & 21 \\
\hline $\begin{array}{l}\text { Trainings for technical staffs } \\
\text { and volunteers }\end{array}$ & 4 & 4 & 2 & 1 & 11 \\
\hline Acquisition of hardware and software & 3 & 4 & 2 & - & 9 \\
\hline More communities support & 2 & 5 & - & 2 & 9 \\
\hline $\begin{array}{l}\text { Mobile applications (Apps) for } \\
\text { data collection and alerts visualization }\end{array}$ & 5 & 2 & - & - & 7 \\
\hline Devices for data collection in the field & 2 & 3 & 1 & - & 6 \\
\hline $\begin{array}{l}\text { Increased Internet accessibility } \\
\text { to local stakeholders }\end{array}$ & 3 & - & - & - & 3 \\
\hline
\end{tabular}

Table 3. Users' needs of technology.

Training opportunities for technical staffs and volunteers were also cited by participants as a basic technology need. Another interesting finding is that more communities support is required to increase technology appropriation for information handling, which is considered a key principle of DRM (Haworth et al., 2016).

\subsection{Policy and standards}

The information management literature suggests that some degree of supportive policies must be established within the organizations to encourage sharing and collaboration on geographic information and practices (Nebert, 2004). In this sense, our results indicated that many of participants' organizations $(40 \%)$ have no strong policies or procedures in place for sharing geographic information for DRM. Another result of this survey is that non-technical aspects might cause restrictions in the exchange of GI for DRM (Figure 5). For instance, about $65 \%$ of participants similarly indicated that restrictive data licenses and confidentiality and intellectual property were the biggest barriers for sharing GI for DRM. In contrast, a few participants (19\%) stated that they do not have any restriction for sharing information.

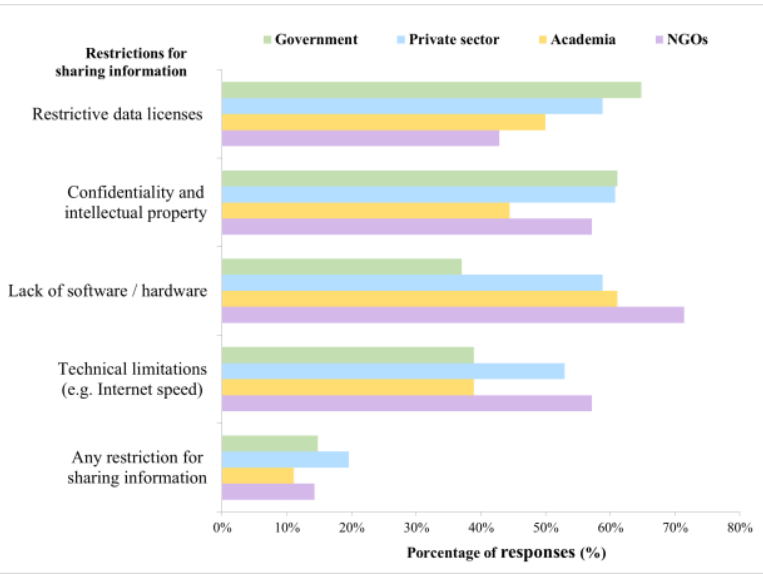

Figure 5. Restrictions for sharing GI for DRM activities.

Note: Multiple answers allowed.
In terms of specific standards for accessing geographic information and services, Web Mapping Service (ISO 19128:2005) and data quality (ISO 19157:2013) standards were the most frequently used by participants, with each at about 81\%. Metadata standards (ISO 19115-1:2014/AMD 1:2018) were also suggested by participants as an essential standard for discovery GI for DRM. These results suggested that participants had a strong awareness of international standards for geographic information. As emphasized by Snoeren, et al. (2007), metadata and data quality standards are necessary to achieve interoperability for sharing GI in case of emergency.

Herein, participants were asked one open question to cite needs of policy and standards matters that should be implemented for sharing of geographic information. Based on our findings, establishing a policy to promote sharing of GI, along with institutional arrangements of agencies involved in providing GI to stakeholders and citizens are essential needs of the DRM community (Table 4). Interestingly, an equal number of participants acknowledged that more users' involvement at the local level and funding to enhance technical capabilities were also essential necessities for GI handling and sharing.

\begin{tabular}{|l|c|c|c|c|c|}
\hline \multicolumn{1}{|c|}{ Necessity of policy and standards } & $\begin{array}{c}\text { GOV } \\
(\mathbf{N}=\mathbf{1 8})\end{array}$ & $\begin{array}{c}\text { PRIV } \\
(\mathbf{N}=\mathbf{1 5})\end{array}$ & $\begin{array}{c}\text { ACAD } \\
(\mathbf{N}=\mathbf{3})\end{array}$ & $\begin{array}{c}\text { NGOs } \\
(\mathbf{N}=\mathbf{6})\end{array}$ & $\begin{array}{c}\text { TOTAL } \\
(\mathbf{N}=\mathbf{4 2})\end{array}$ \\
\hline $\begin{array}{l}\text { Established a policy for sharing geo- } \\
\text { information between public institutions } \\
\text { and citizens }\end{array}$ & 3 & 2 & 3 & 3 & 11 \\
\hline $\begin{array}{l}\text { Institutional arrangements of agencies } \\
\text { involved in providing geographic } \\
\text { information }\end{array}$ & 5 & 4 & - & - & 9 \\
\hline $\begin{array}{l}\text { Opportunities for training and technical } \\
\text { documentations }\end{array}$ & 2 & 3 & - & - & 5 \\
\hline $\begin{array}{l}\text { Build a culture of trust and collaboration } \\
\text { for information sharing }\end{array}$ & 1 & 2 & - & 2 & 5 \\
\hline $\begin{array}{l}\text { More users involvement at the local } \\
\text { level }\end{array}$ & 3 & & - & 1 & 4 \\
\hline $\begin{array}{l}\text { Technical standards for information and } \\
\text { maps dissemination and access network }\end{array}$ & 3 & 1 & - & - & 4 \\
\hline $\begin{array}{l}\text { Funding for hardware and software } \\
\text { acquisition }\end{array}$ & 1 & 3 & - & - & 4 \\
\hline
\end{tabular}

Table 4. Users' needs of policy and standards.

\subsection{Human resources}

Human resources often pose major constraints on the use of GI for rapid response in case of disasters (Cutter, 2003). This survey section started asking participants to mention their availability of knowledge resources to facilitate technology integration for DRM. A majority of participants (80\%) claimed to use technical specifications as a way to ease the deployment of GI technology.

Up to $53 \%$ of participants stated that assessment of users' needs of GI and services oriented to key local stakeholders was necessary. Regarding the necessity to include missing stakeholders to foster the generation of information and services for DRM, our survey results revealed that there is a growing recognition of the value that should be added by the private sector $(91 \%)$ and professional associations $(80 \%)$ to the DRM efforts, particularly at the local level. University (92\%) and NGOs (82\%) were also cited as important missing stakeholders (Figure 6). 


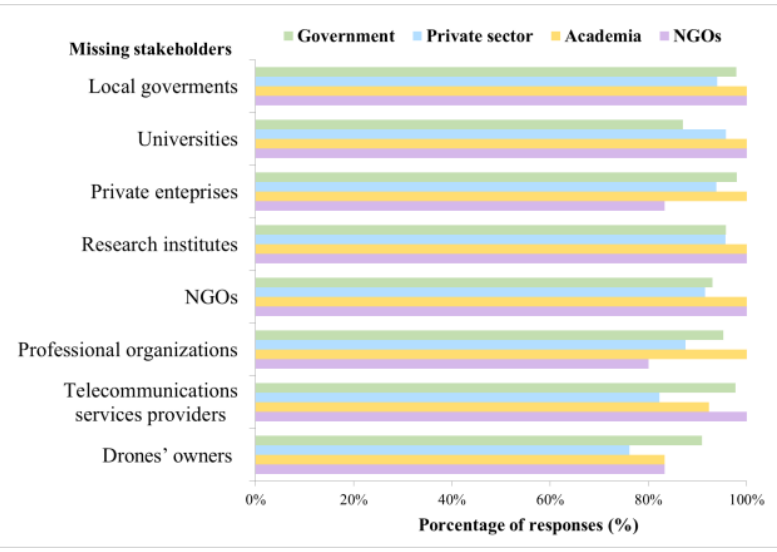

Figure 6. Missing stakeholders for generating GI for DRM. Note: Multiple answers allowed.

In term of specific capacity building initiatives to enhance human resources for DRM, participants were asked to rank using a four-point Likert scale (ranging from not important to very important), a list of trainings on geospatial technologies. Interestingly, an equal number of participants (74\%) ranked trainings on metadata, geodatabase management and spatial data infrastructure as very important. In particular, trainings on Bigdata were rated as very important by participants from government $(81 \%)$ and academia $(64 \%)$.

At the end of this survey section, one open question asked participants to mention priority needs that ought to be tackled to achieve more citizens and institutions involvement in generating and sharing GI for DRM. Most participants suggested that information technologies and social networks are necessary tools to underpin non-traditional stakeholders' participation in providing and disseminating local spatial knowledge from the territory for rapid DRM decisions (Table 5).

The survey results also revealed that building a culture of organizational understanding and technical cooperation were identified as basic needs for generating an agile and relevant flow of geographic information and services to enhance decision-making processes. This result is of major interest to us, because cultural and social behaviors of the response community might prevent the adoption of GI technologies in disaster and emergency management (Cutter, 2003).

\begin{tabular}{|l|c|c|c|c|c|}
\hline \multicolumn{1}{|c|}{ Necessity of human resources } & $\begin{array}{c}\text { GOV } \\
(\mathbf{N}=\mathbf{1 7})\end{array}$ & $\begin{array}{c}\text { PRIV } \\
(\mathbf{N}=\mathbf{1 4})\end{array}$ & $\begin{array}{c}\text { ACAD } \\
(\mathbf{N}=\mathbf{3})\end{array}$ & $\begin{array}{c}\text { NGOs } \\
(\mathbf{N}=\mathbf{9})\end{array}$ & $\begin{array}{c}\text { TOTAL } \\
(\mathbf{N}=\mathbf{4 3})\end{array}$ \\
\hline $\begin{array}{l}\text { Effective communication among } \\
\text { stakeholders and citizens using social } \\
\text { networks }\end{array}$ & 3 & 4 & 1 & 2 & 10 \\
\hline $\begin{array}{l}\text { Building a culture that encourage more } \\
\text { cooperation among agencies in charge of } \\
\text { providing information services }\end{array}$ & 4 & 4 & - & 2 & 10 \\
\hline $\begin{array}{l}\text { More trainings in geographic } \\
\text { technologies oriented to technical staffs } \\
\text { and local leaders using virtual platform }\end{array}$ & 4 & 2 & 1 & 2 & 9 \\
\hline More community participation & 3 & 2 & & 2 & 7 \\
\hline Involvement of private enterprises & 1 & 2 & - & 1 & 4 \\
\hline $\begin{array}{l}\text { Research on users' requirements } \\
\text { in disaster prone areas }\end{array}$ & 2 & - & 1 & - & 3 \\
\hline
\end{tabular}

Table 5. Users' needs of human resources. Note: Multiple answers allowed.
Our results also confirm previous claims that social networks, along with virtual collaborative platforms, are effective mechanisms for connecting people and exchanging of best practices from spatially distributed stakeholders, leading to construct disaster resilience in a society (Haworth, et al., 2016).

This survey ended by asking the participants an open question to indicate missing elements that had to be tackled in this questionnaire. A large majority of participants agreed on the completeness of the survey, covering most of the important aspects for the adoption of GI and services for DRM. Nonetheless, three (3) participants stated that the identification of the most central source of information, local capacity and the role of real-time sensors network were missing in the survey.

\section{SUMMARY AND CONCLUSIONS}

Research on identification of user's requirements for disaster risk reduction spans a broad range of technical, social and institutional issues. This research has been focus on identifying users' requirements of geospatial information and services that are necessary in view of being better prepared for future multidisaster risk management scenarios in the Dominican Republic.

We identified these requirements by conducting a national level online survey questionnaire, from February to March 2020, targeted to expert and non-expert users of geographic information and technologies applied to DRM.

Our results should help policy-makers, practitioners and community leaders to better understand what technical and nontechnical issues must be tackled in advance to facilitate the utilization of GI and services in building a more resilience society for future multi-hazard disaster risk management scenarios in the Dominican Republic.

Based on our current research, we have identified seven major users' requirements to better enabling geographic information and services for DRM in the Dominican Republic, as following:

1. Establishing a sound policy for sharing geoinformation and services between public institutions and citizens;

2. Implementing a national SDI that meet stakeholders' needs for multi-disaster risk scenarios;

3. Technical standards for real-time data collection and dissemination;

4. Simplified procedures for gathering and accessing metadata;

5. Developing mobile applications (App) for data collection and alerts visualization;

6. More capacity building programs on collaborative mapping techniques at the local level; and,

7. Enabling closer community participation using social networks and virtual platforms. 
There are some limitations in our research approach. First, the limited number of stakeholders studied from academia, NGOs and local governments might be considered as a concern. This might restrict the extrapolation of the findings to a broader domain. Furthermore, first response personnel, disaster managers and representatives from international aid agencies were likely underrepresented in the study. However, the paucity of existing literature on the region and the need for relevant information on the topic justify the approach. This research might be relevant not only for developing states in the Caribbean region, but also to the scientific community for the other Small Island Developing States in the World.

This research provided a better insight on the functionality and performance characteristic of the geo-information, technology, policy and standards, and human resources, necessary to deliver a common operational picture of the territory for disaster risk management in the Dominican Republic.

This work highlighted that there is an increasing recognition of the value of citizens' participation in adopting geographic information and technologies for DRM. This work also highlighted the necessity of more institutional arrangements to facilitate collaboration between agencies in charge of delivering information services for DRM.

Future research will focus on the identification of users' requirements of GI and services to spatially enabling small and medium-sized enterprises in DRM efforts in Small Island Developing States context.

\section{ACKNOWLEDGEMENTS}

This research was funded by the Ministry of Higher Education, Science and Technology (MESCYT) and the National Geological Survey of the Dominican Republic, under the grant number: FONDOCYT 2018-2019-1E3-065, in which this paper is a result. We specially wish to thank the contribution of all participants of the survey, which forms the basis for this research. We owe special thanks to all Its4DRM research team members for their valuable comments and suggestions. We also acknowledge the comments by three anonymous reviewers that helped to improve the manuscript.

\section{REFERENCES}

Ajmar, A., Boccardo, P., Disabato, F., \& Giulio Tonolo, F. (2015). Rapid Mapping: geomatics role and research opportunities. Rendiconti Lincei. Scienze Fisiche e Naturali, 26, 63-73. https://doi.org/10.1007/s12210-015-0410-9

Carley, K. M., Malik, M., Landwehr, P. M., Pfeffer, J., \& Kowalchuck, M. (2016). Crowd sourcing disaster management: The complex nature of Twitter usage in Padang Indonesia. Safety Science, 90, 48-61.

CRED EM-DAT. (2020). The International Disaster Database. Retrieved June 1, 2020, from http://www.emdat.be/

Cutter, S. L. (2003). GI Science, Disasters, and Emergency Management. Transactions in GIS, 7(4), 439-446. https://doi.org/10.1111/1467-9671.00157
Diehl, S., Neuvel, J., Zlatanova, S., \& Scholten, H. (2006). Investigation of user requirements in the emergency response sector: the Dutch case. In Proceedings of the second Gi4DM (Vol. 2000, pp. 25-26). Goa, India. Retrieved from http://www.gdmc.nl/publications/2006/User_requirements_eme rgency_response_sector.pdf

Eide, A. W., Haugstveit, I. M., Halvorsrud, R., Skjetne, J. H., \& Stiso, M. (2012). Key challenges in multi-agency collaboration during large-scale emergency management. In SINTEF Digital / Software and Service Innovation (Vol. 953). Retrieved from http://ceur-ws.org/Vol-953/

Genovese, E., \& Stéphane, R. (2010). Potential of VGI as a Resource for SDIs in the North/South Context. Geomatica, 64, 439-450.

Goldblatt, R., Jones, N., \& Mannix, J. (2020). Assessing OpenStreetMap completeness for management of natural disaster by means of remote sensing: A case study of three small Island States (Haiti, Dominica and St. Lucia). Remote Sensing, 12(1). https://doi.org/10.3390/RS12010118

Hatfield Consultants. (2019). Canadian Geospatial Data Infrastructure (CGDI) user needs assessments. https://doi.org/https://doi.org/10.4095/314606

Haworth, B., Whittaker, J., \& Bruce, E. (2016). Assessing the application and value of participatory mapping for community bushfire preparation. Applied Geography, 76, 115-127.

J. Menold, L. Weizler, Y. Liu, S. G. B. and S. M. (2015). Identifying end-user requirements for communication systems in disadvantaged environments. In 2015 IEEE Global Humanitarian Technology Conference (pp. 284-291). Seattle, WA.

Katalin, T., Clemens, P., Andreas, I., Michael, L., \& Maria, N. de L. (2012). A Conceptual Model for Developing Interoperability Specifications in Spatial Data Infrastructures. https://doi.org/10.2788/21003

Keiko, T., \& Hayashi, H. (2012). Geospatial Information Improves the Decision-Making Process during the Disaster Response: The Experience of the Emergency Mapping Team in the 2011 off the Pacific Coast of Tohoku Earthquake Takashi. In 15th World Conference on Earthquake Engineering. Lisbon, Portugal.

López-Marrero, T., Hampton, J., Vergara, E., Quiroz, J., Simovic, K., \& Arevalo, H. (2013). Hazards and disasters in the Insular Caribbean: A systematic literature review. Caribbean Geography, 18(September), 85-105.

Maguire, M., \& Bevan, N. (2002). User requirements analysis: A review of supporting methods. Proceedings of IFIP 17th World Computer Congres, (August), 133-148. https://doi.org/10.1007/978-0-387-35610-5_9

MEPyD. (2012). Estrategia Nacional de Desarrollo 2030. Santo Domingo, Dominican Republic: Ministerio de Economía, Planificación y Desarrollo. Retrieved from http://200.88.158.22/mepyd/estrategia-nacional-de-desarrollo2030/ 
Munenari, I., Reo, K., Keiko, T., \& Haruo, H. (2012). Proposing Effective Method to Develop Common Operational Picture in Disaster Response Utilizing Cloud-based Geospatial Infrastructure. International Journal for Infonomics (IJI), $5(3 / 4), 663-668$.

National Bureau of Statistic. (2010). IX Censo Nacional de Población y Vivienda 2010. Retrieved from http://censo2010.one.gob.do/

National Congress. (2002). Ley No. 147-02 sobre Gestión de Riesgos. Santo Domingo, Dominican Republic. Retrieved from http://www.defensacivil.gob.do/transparencia/baselegal/item/ley-147-02-gestion-de-riesgos

National Geological Survey. (2015). Estudio de la Amenaza Sísmica y Vulnerabilidad Física del Gran Santo Domingo. Retrieved from http://sgn.gob.do/index.php/servicios/noticias/ item/consultoria-especialista-en-norma-sismica-2

Nebert, D. D. (2004). The SDI Cookbook. (D. D. Nebert, Ed.). Technical Working Group Chair, GSDI.

PreventionWeb. (2014). Dominican Republic Disaster \& Risk Profile. Retrieved from http://www.preventionweb.net/ countries/dom/data

Rosario Michel, G., Muñoz Tapia, S., Manzano Aybar, F., Guzmán Javier, V., \& Crompvoets, J. (2020). Identifying Users' Requirements for Emergency Mapping Team Operations in the Dominican Republic. ISPRS International Journal of GeoInformation, 9(3), 165. https://doi.org/10.3390/ijgi9030165

Snoeren, G., Zlatanova, S., Crompvoets, J., \& Scholten, H. (2007). Spatial Data Infrastructure for emergency management : the view of the users (pp. 1-12).

UNISDR. (2015a). Making Development Sustainable: The Future of Disaster Risk Management. Global Assessment Report on Disaster Risk Reduction. Geneva, Switzerland: United Nations Office for Disaster Risk Reduction (UNISDR).

UNISDR. (2015b). Sendai Framework for Disaster Risk Reduction 2015 - 2030. Geneva, Switzerland: United Nations Office for Disaster Risk Reduction (UNISDR).

World Bank. (2019). Dominican Republic Overview. Retrieved September 4, 2019, from http://www.worldbank.org/en/ country/dominicanrepublic/overview

Revised October 20, 2020 